\title{
A possible route for lymphocyte migration into diseased tissues
}

\author{
AJ FREEMONT \\ From the Department of Pathology, University of Manchester Medical School, Oxford Road, Manchester M13 \\ 9PT
}

SUMMARY Vessels within the lymphocytic infiltrate in 161 examples of 24 different diseases have been studied using light and electron microscopy and histochemistry. Hitherto undescribed venules have been identified within lymphocyte aggregates which exhibit a structure, ultrastructure and cytochemistry previously believed to be restricted to the high endothelial venules of lymphoid tissues. The significance of these findings is discussed within the context of lymphocyte migration into abnormal tissue.

Tissue lymphocyte infiltration occurs in response to many different pathological stimuli. Although their function is often unclear, lymphocytes are believed to play an important part in initiating and modifying disease processes. Despite their importance, little is known of the factors stimulating and controlling lymphocyte migration from blood into the affected tissue.'

Physiological lymphocyte migration, into lymphoid tissue, has been intensively studied over the past few years. ${ }^{23}$ In these organs lymphocyte traffic from blood occurs, almost exclusively, across the walls of specialised venules ${ }^{4}$ which have a unique morphology and histochemistry. ${ }^{56}$ Vessels with these characteristics have not been described outside the lymphoid organs in health, but vessels with a similar ultrastructure have been found in experimentally induced chronic inftammation in laboratory animals, ${ }^{7}$ raising the possibility that vascular specialisation for accelerated lymphocyte diapedesis may not be restricted to the lymphoid organs.

In this study a number of human diseases with an associated lymphocytic infiltrate have been examined to determine if any of the local blood vessels exhibit features suggestive of specialisation for selective lymphocyte traffic from circulation to tissue.

\section{Material and methods}

The study material consisted of biopsies from 161 patients with various pathological conditions associated with lymphocytic infiltrates. In every case, tissue was processed for paraffin wax embedding and, where possible, samples were taken for histochemistry and electron microscopy (Table 1).

PARAFFIN WAX EMBEDDING

After fixation in $10 \%$ neutral buffered formalin,

Table 1 Those diseases with lymphocytic infiltrates showing the numbers examined using various techniques.

\begin{tabular}{lrrr}
\hline Disease & \multicolumn{3}{c}{ No of cases } \\
\cline { 2 - 4 } & LM & Histochem & $E M$ \\
\hline Foreign body reactions & 18 & 7 & 3 \\
Peptic ulceration & 15 & 1 & 1 \\
Ulcerative colitis & 12 & 2 & 2 \\
Rheumatoid synovium & 9 & 1 & 8 \\
Parotitis & 7 & 2 & 2 \\
Chronic cholecystitis & 5 & 1 & 1 \\
Myositis & 4 & 4 & 0 \\
Reiter's synovium & 1 & 0 & 0 \\
Chronic pyelonephritis & 3 & 0 & 0 \\
Oesophageal SCC & 4 & 2 & 2 \\
Adenocarcinoma of thyroid & 3 & 1 & 1 \\
Adenocarcinoma of stomach & 5 & 2 & 2 \\
Medullary carcinoma of breast & 6 & 1 & 1 \\
IDC breast & 20 & 6 & 8 \\
Seminoma & 9 & 4 & 2 \\
Basal cell carcinoma & 7 & 4 & 4 \\
Transitional cell carcinoma of bladder & 9 & 3 & 3 \\
Thyroid adenoma & 4 & 3 & 3 \\
Large bowel adenoma & 1 & 1 & 1 \\
Adenolymphoma & 10 & 4 & 4 \\
Benign prostatic hyperplasia & 5 & 1 & 2 \\
Coeliac disease & 1 & 1 & 1 \\
Cystic hypertrophic mastopathy & 1 & 1 & 1 \\
Lichen planus & 1 & 0 & 0 \\
Hashimoto's thyroiditis & 1 & 1 & 1 \\
Total & 161 & 53 & 53 \\
\hline
\end{tabular}

$\mathrm{LM}=$ paraffin embedding. Histochem $=$ non-specific esterase histochemistry. $\mathrm{EM}=$ electron microscopy. 
tissue was embedded in paraplast, sectioned at $3 \mu \mathrm{m}$ and stained with haematoxylin, methyl green pyronin and periodic-acid Schiff (PAS) using standard techniques. Metachromasia was detected with azure A employing the method described by Ball and Jackson. ${ }^{8}$ For this, prior to staining, one section from each case was pretreated with crystalline ribonuclease (Sigma) at a concentration of $1 \mathrm{mg} / \mathrm{ml}$ in phosphate buffer $\mathrm{pH} 6$ for $3 \mathrm{~h}$ at $37^{\circ} \mathrm{C}$ and another was treated with phosphate buffer without ribonuclease under the same conditions for the same time.

\section{ENZYME HISTOCHEMISTRY}

Cubes of unfixed tissue $\left(5 \mathrm{~mm}^{3}\right)$ were immersed in ice-cold formol sucrose and after $18 \mathrm{~h}$ transferred to Holt's syrup. ${ }^{9}$ Cryostat sections $(7 \mu \mathrm{m})$ were cut the following day and a simultaneous coupling azo-dye technique employed for localising the enzyme nonspecific esterase (NSE). This emṕloyed a method devised in this laboratory ${ }^{10}$ whereby tissue sections are incubated at $37^{\circ} \mathrm{C}$ with $\alpha$-naphthyl propionate for $30 \mathrm{~min}$, the position of the final reaction product being displayed with fast garnet GBC.

\section{ELECTRON MICROSCOPY}

Small portions of tissue were fixed for $4 \mathrm{~h}$ in $2.5 \%$ glutaraldehyde in $0 \cdot 1 \mathrm{M}$ sodium cacodylate buffer $\mathrm{pH}$ 7.4 at room temperature. The specimens were then washed in $0.1 \mathrm{M}$ cacodylate buffer and minced into 1 $\mathrm{mm}^{3}$ cubes. This was followed by postfixation in $1 \%$ osmium tetroxide in cacodylate buffer $\mathrm{pH} 7.4$ at $4^{\circ} \mathrm{C}$

Table 2 The normal and diseased tissues (without lymphocytic infiltrates) used for comparison with those diseases in Table 1. The column headings are the same as in Table 1

\begin{tabular}{lrrr}
\hline Tissue & \multicolumn{3}{l}{ No of samples } \\
\cline { 2 - 4 } & LM & Histochem & EM \\
\hline Normal tissue & 43 & 17 & 12 \\
Skin & 15 & 3 & 1 \\
Breast & 8 & 5 & 5 \\
Oesophagus & 5 & 1 & 1 \\
Prostate & 1 & 0 & 1 \\
Large bowel & 6 & 1 & 1 \\
Synovium & 2 & 2 & 2 \\
Thyroid & 2 & 1 & 0 \\
Muscle & 4 & 4 & 1 \\
Diseased tissue & 66 & 29 & 31 \\
Granulation tissue & 26 & 13 & 18 \\
Synovium in septic arthritis & 3 & 0 & 0 \\
Breast carcinoma & 12 & 5 & 6 \\
Oesophagus SCC & 2 & 0 & 1 \\
Prostatic adenocarcinoma & 1 & 1 & 1 \\
Transitional cell carcinoma of bladder & 2 & 1 & 2 \\
Parathyroid adenoma & 6 & 1 & 0 \\
Benign prostatic hyperplasia & 4 & 1 & 2 \\
Lipoma & 1 & 1 & 1 \\
Myocardial infarction & 3 & 0 & 0 \\
Muscular dystrophy & 6 & 6 & 0 \\
Myon & & & \\
\hline
\end{tabular}

for $90 \mathrm{~min}$, dehydration in graded alcohols and propylene oxide and embedding in Emix resin. Sections $(0.5 \mu \mathrm{m})$ were cut and stained with $1 \%$ toluidine blue in borax and suitable areas selected for ultrathin sectioning. Grids were double-stained using uranyl acetate and Reynold's lead citrate and examined in a Philips' 301 electron microscope.

For comparison, samples of normal tissues and diseased tissues without lymphocytic infiltrates were also examined by light and electron microscopy using identical processing protocols (Table 2).

\section{Results}

Although the majority of small blood vessels in the diseased tissues had an identical morphology and histochemistry to those flat endothelium-lined vessels found in normal tissue, areas of lymphocyte aggregation also contained another small, but easily distinguishable, population of vessels. These vessels had the general appearances of venules (Fig. 1), varied from $20 \mu \mathrm{m}$ to $100 \mu \mathrm{m}$ in diameter, were lined by between three and 10 cells in transverse section and, whilst distributed throughout areas of lymphocytic infiltration, were found most commonly at their periphery.

The number and size of the vessels varied with the lymphocyte density. They were readily seen when the numbers of lymphocytes exceeded $150 / \mathrm{mm}^{2}$ but semiserial sectioning was often required to demonstrate their presence when the density was lower, and none

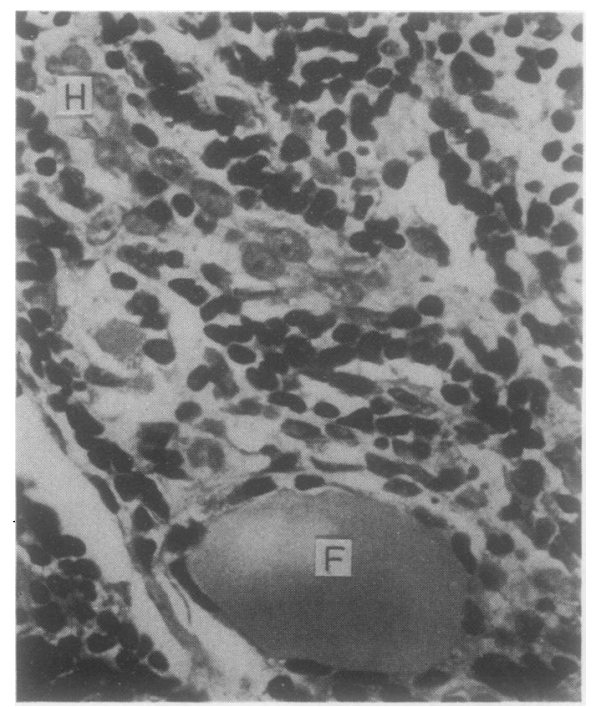

Fig. 1 A high endothelium lined vessel with lymphocytes in its lumen and wall $(H)$ and a residual follicle $(F)$ from a case of Hashimoto's thyroiditis. Haematoxylin and eosin $\times 300$. 
was seen in the absence of lymphocytes in either normal or diseased tissues.

When stained with haematoxylin and eosin the endothelial cells were shown to differ from endothelium elsewhere. The cells were much plumper, the nuclei open and ovoid with a single, central violet nucleolus and a peripheral rim of dark blue chromatin. The cytoplasm was more abundant than in other endothelial cells but tended to vary from one cell to the next, occasionally producing a cuboidal profile (Fig. 2). The cells lay on a thick densely eosinophilic

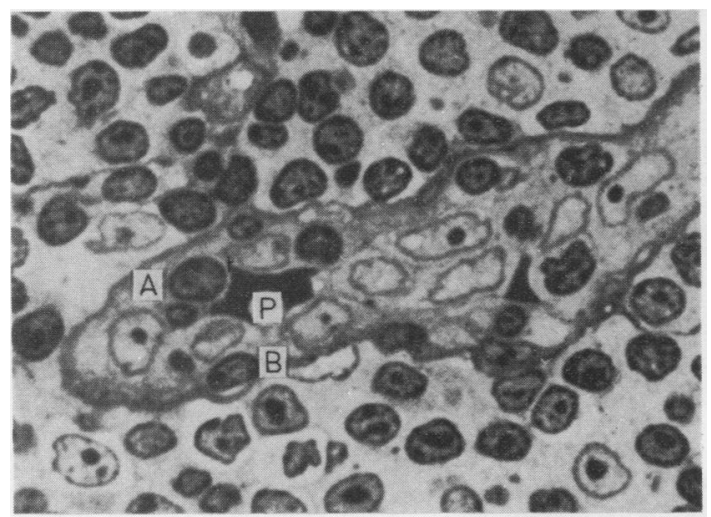

Fig. 2 A plump endothelium lined vessel $(P)$ showing the nuclear morphology, cytoplasmic volume, thick basement membrane and intramural lymphocytes $(A \& B)$. From a case of medullary carcinoma of breast $\times 1100$.

basement membrane with an irregular outer border. Within the lumen, between the endothelial cells, within the basement membrane and surrounding the vessels, often in concentric circles, were large numbers of lymphocytes.

Cytoplasmic metachromasia could be demonstrated with azure $\mathrm{A}$ and was abolished by pretreating the sections with ribonuclease. The cytoplasm was also pyroninophilic, unlike that of the flattened endothelial cells and the basement membrane stained strongly with PAS.

Non-specific esterase was demonstrated in the vessels giving an intense diffuse cytoplasmic reaction in the endothelial cells (Fig. 3). The only other types of vessels with any degree of non-specific esterase positivity were arterioles, but here the stain was weak and restricted to a few perinuclear granules.

Although in many respects the plump endothelium differed from the more common flat endothelium only in a quantitative manner ultrastructurally, certain features found in the former were absent from the latter. The plump endothelial cells were charac- teristically squamous or cuboidal (Fig. 4), the cytoplasm having the appearance of ground glass. The nuclear morphology reflected the appearances seen with the light microscope with the exception that in preparations for electron microscopy, some nuclei showed surface irregularities and occasionally deep narrow clefts (Fig. 4).

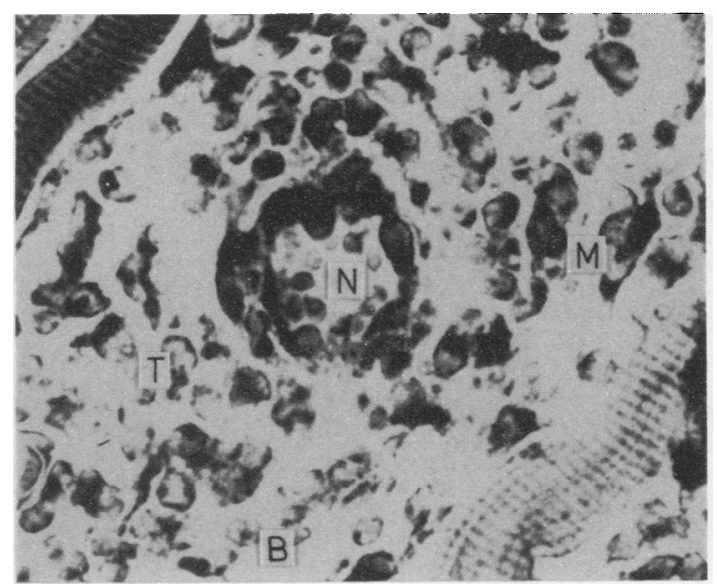

Fig. 3 A non-specific esterase positive vessel $(N)$ within the chronic inflammatory infiltrate from a case of myositis. Macrophages $(M)$ are also densely NSE + ve and $T$ lymphocytes $(T)$ have esterase positive cytoplasmic granules. Other lymphocytes $(B)$ are negative $\times 400$.

Many mitochondria were present in the cytoplasm as were frequent cisternae of rough endoplasmic reticulum often in conjunction with Golgi vesicles. The major cytoplasmic components were large numbers of free ribosomes between which ran fine myofilaments. Several different membrane bound vesicular structures were seen in the cytoplasm including residual bodies with heterogeneous contents, Wiebel-Palade bodies and multivesicular bodies with up to 20 vesicles of variable size in a dense matrix (Fig. 5). Absence of intercellular junctions was noticeable although at the bases of the cells blunt lateral interdigitations were seen.

The thickened basement membrane described at light microscopy was found to consist of a complex of basement membrane, collagen fibres, and pericyte processes.

Lymphocytes were found within the lumen of the vessels, between the endothelial cells and within the basement membrane complex (Fig. 4) where they were often compressed circumferentially about the vessel. These cells were almost invariably small lymphocytes but very occasional transformed lymphocytes were also seen in the vessel wall. 


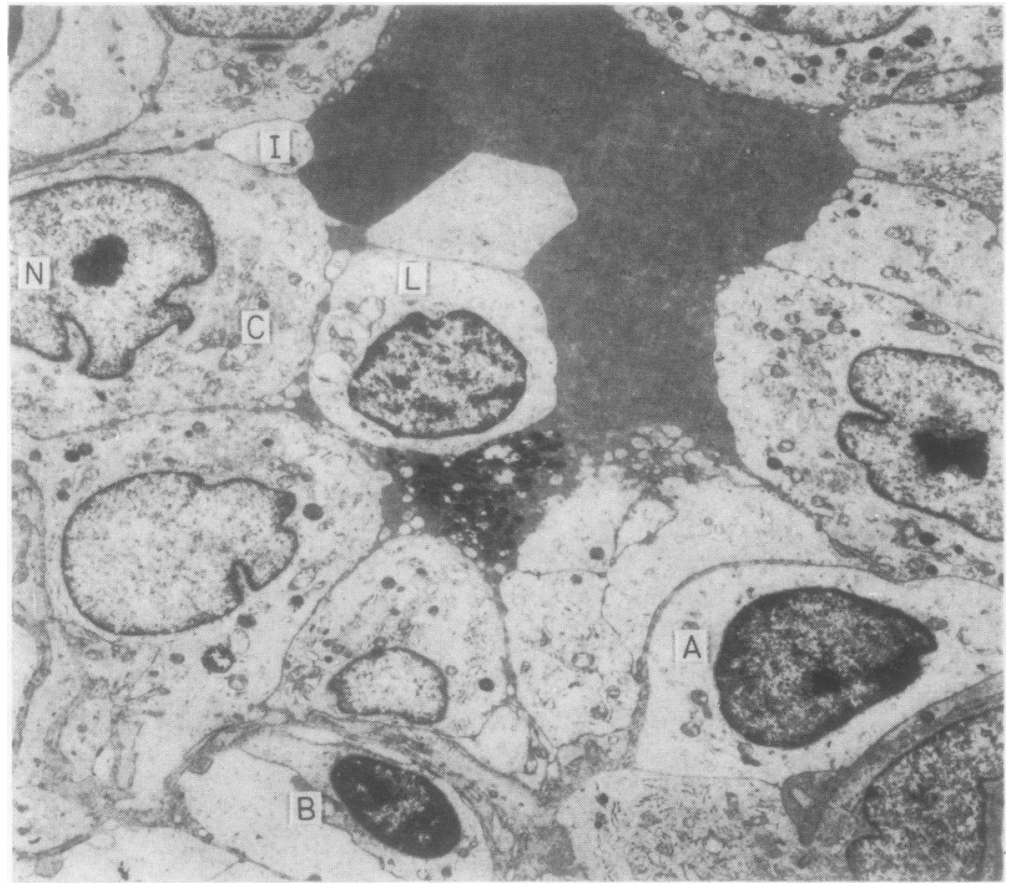

Fig. 4 A transverse section

through a high endothelium-like venule for the synovium of a patient with Reiter's disease. Clefts in the nuclear envelope $(N)$ and an organelle cluster $(C)$ in the cytoplasm adjacent to an intraluminal lymphocyte $(L)$ can be seen. $A$ lymphocyte process (I) lies between two endothelial cells and two other lymphocytes are present one $(A)$ between an endothelial cell and the basement membrane complex and another $(B)$ within the complex $\times 4000$.

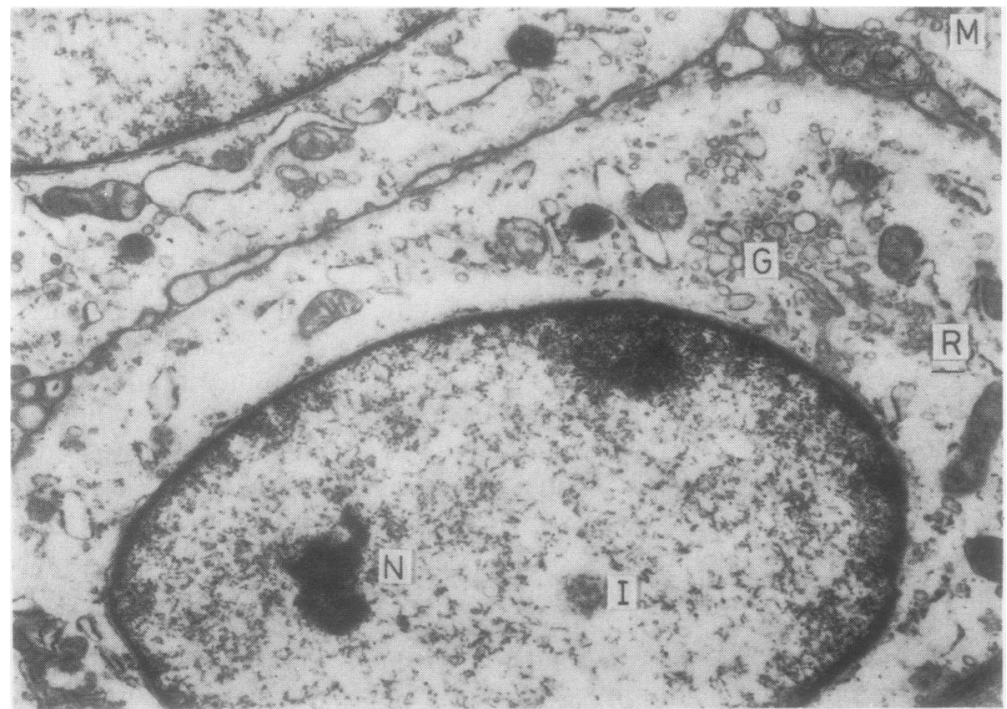

Fig. 5 Parts of three endothelial cells showing multivesicular bodies $(M)$, an organelle cluster containing Golgi vesicles $(G)$, rough endoplasmic reticulum $(R)$ and mitochondria and nuclear features such as the prominent nucleolus $(N)$ and an intranuclear body $(I) \times 9100$.

\section{Discussion}

Lymphocytic infiltrates have been described as part of many different diseases, both inflammatory and neoplastic, but the numbers of lymphocytes are frequently variable, in otherwise identical lesions. Despite reports of important prognostic implications for this variability, "12 little is known of its cause and even the factors responsible for the initiation and control of lymphocyte migration into the tissue are only poorly understood.

In experimental models of chronic inflammation infiltrating lymphocytes have been shown to come from the circulating pool through local blood vessel 
walls; ${ }^{13}$ a situation analogous to that normally operating in lymph nodes. Here circulating lymphocytes selectively migrate into the internal labyrinth of the node by passage across the walls of specialised venules in the paracortex known as high endothelial venules ${ }^{14}$ (HEV) because of the unusual plumpness of their endothelial cells.

HEV were first described in $1898^{15}$ and subsequent studies in laboratory animals have shown, not only that they represent the sole site at which circulating lymphocytes enter the node, but also that they have a unique structure, ${ }^{16}$ ultrastructure ${ }^{1718}$ and histochemistry, ${ }^{19}$ which distinguishes them from all other blood vessels.

In a recent description of human HEV, several morphological and cytochemical features were reported to be peculiar to these vessels. ${ }^{20}$ These features include some which may be demonstrated in paraffin-embedded tissue using routine stains. HEV are recognisable as venules lined by large endothelial cells, frequently cuboidal in shape, containing pale open nuclei, with a single central nucleolus, copious cytoplasm which displays pyroninophilia and ribonuclease labile metachromasia and a thick basement membrane staining strongly with eosin and PAS.

Other distinguishing characteristics are the intense granular cytoplasmic reaction for non-specific esterase in the endothelial cell cytoplasm and the ultrastructural appearances. These latter include biosynthetic organelle clusters containing Golgi vesicles, rough endoplasmic reticulum and mitochondria, much cytoplasmic RNA in the form of free ribosomes, numerous cytoplasmic myofilaments, frequent membrane-bound lysosomal structures (residual bodies and multivesicular bodies), an absence of cell junctions and a basement membrane, interwoven collagen fibres and pericytes. Of particular note are the large numbers of lymphocytes in the vessel lumina and within the various layers of their walls.

Several investigators have suggested the specialised function and unique microscopic appearances may be linked and a few have demonstrated a relation between metabolism, structure and lymphocyte diapedesis. ${ }^{21}$ On the basis of these studies, it is becoming apparent that not only do structural and cytochemical characteristics distinguish this set of blood vessels, with specialised function, from all others but that they also represent an integral part of that function.

This correlation of function and structure raises the possibility that, within the context of lymphocyte migration into any tissue, vessels exhibiting the microscopic features of HEV may share their specialised function.

In this study a population of blood vessels, exhibiting those features previously reported as specific to HEV, has been identified in the lymphocytic infiltrates associated with several completely unrelated disease states and may therefore, represent the site at which circulating lymphocytes gain access to the tissue.

As it has not proved possible to obtain direct evidence for these HEV-like vessels being the route of lymphocyte migration into infiltrates in humans, evidence for this function is only circumstantial; nevertheless there are a number of observations which would support this possibility. Firstly, the vessels are identical in all histological respects to lymph node HEV; secondly, they have a more intimate relation with lymphocytes than all other vessels; thirdly, vessels with the characteristics of HEV are not found in normal tissue, nor indeed outside areas of lymphocyte infiltration in diseased tissues and, finally, serial sections show that infiltrates containing significant numbers of lymphocytes $\left(>150 / \mathrm{mm}^{2}\right)$ will always contain vessels of this sort.

Thus there would appear to be a small, hitherto undescribed, group of venules within areas of lymphocytic infiltration which may well be the site at which lymphocytes preferentially enter the tissue. These vessels may be recognised by their distinctive microscopic appearances, shared only by the HEV of lymphoid tissues.

The HEV-like vessels cannot be the only site at which circulating lymphocytes enter tissue as lymphocyte migration through healthy tissues, which do not contain these vessels, is well recognised. It is more probable that they represent a local vascular response facilitating the rapid transfer of lymphocytes into the diseased area. Whilst they suggest a possible route for lymphocyte migration from blood to diseased tissues, these observations apparently offer no direct information about its control; however, similarities between HEV and the vessels in lymphocytic infiltrates may indicate that the mechanisms by which HEV are believed to influence lymphocyte diapedesis may also apply to the HEVlike vessels.

I am indebted to Dr CJP Jones for her assistance in producing the electronmicrographs and to the Manchester Central District Grants Committee for their support of this work.

\section{References}

\footnotetext{
' Edwards SJ, Rowlands GF, Lee MR. Reduction of lymphocyte transformation by a factor produced by gastrointestinal cancer. Lancet 1973; i:687-9.

' Schoeff GI. The migration of lymphocytes across the vascular endothelium in lymphoid tissue. A re-examination. J Exp Med 1972;136:568-8.
} 
"Wenk EJ, Oric D, Reith E, Rhodin JAG. The ultrastructure of mouse lymph node venules and the passage of lymphocytes across their walls. J Ultrastruct Res 1974;47:214-41.

+ Gowans JL, Knight EJ. The route of recirculation of lymphocytes in the rat. Proc $R$ Soc Lond [Biol] 1964;159:257-82.

${ }^{s}$ Schumaker $\mathrm{S}$ von. Ueber Phagocytose und die Abfürwege der Leucocyten in den Lymphdrussen. Archiv für mikroskopische Anatomie und Entwicklungsmechanik 1899;54:311-29.

- Smith C. Henon BK. Histological and histochemical study of high endothelium of post-capillary veins of the lymph node. Anat Rec 1959;135:207-13.

' Smith JB, McIntosh GH. Morris Bede. The migration of cells through chronically inflamed tissues. J Pathol 1970;100:21-9.

${ }^{*}$ Ball J, Jackson DS. Histological, chromatographic and spectrophotometric studies of toluidine blue. Stain Technol 1953;28:33-40.

${ }^{\vartheta}$ Holt SJ, Hobbiger EE, Pawan GL. Preservation of rat tissues for cytochemical staining purposes. J Biophys Biochem Cytol 1960;7:383-6.

"' Freemont AJ, Davies SJ. Acid esterase activity in lymphocytes and other cells: a comparison of six alpha-naphthyl-based substrates. Med Lab Sci 1982;39:405-7.

" Underwood JCE. Lymphoreticular infiltrations in human tumours: prognostic and biological implications: a review. $\mathrm{Br} \mathrm{J}$ Cancer 1974;30:538-48.

12 Bloom HJG, Richardson WW, Field JR. Host resistance and survival in carcinoma of breast: a study of 104 cases of medullary carcinoma of breast followed for 20 years. Br Med J 1970;i:1818.

1.3 Graham RC, Shannon SL. Peroxidase arthritis. II, lymphoid cellendothelial interactions during a developing immunologic inflammatory response. Am J Pathol 1972;69:7-24.
${ }^{1+}$ Claesson MO. Jorgensen O. Ropke C. Light and electron microscopic studies of the paracortical post-capillary high endothelial venules. Z Zellforsch Mikrosk Anat 1971;119:195207.

is Thome R. Endothelien als Phagocyten (aus den Lymphdrussen von Macacus cynomalgus). Arch Microsk Anat 1898;52:820-41.

${ }^{10}$ Schulze W. Untersuchungen uber die Capillaren und postcapillaren Venen lymphatische Organe. Z Anat 1925;76:421-62.

17 Anderson AO. Anderson N. Studies on the structure and permeability of microvasculature in normal rat lymph nodes. Am J Pathol 1975;80:387-418.

${ }^{1 *}$ Ropke C, Jorgensen O, Claesson MH. Histochemical studies of high-endothelial venules of lymph nodes and Peyer's patches in the mouse. Z Zellforsch Mikrosk Anat 1972;131:287-97.

${ }^{14}$ Anderson ND, Anderson AO, Wyllie RG. Specialised structure and metabolic activities of high endothelial venules in rat lymphatic tissues. Immunology 1976;31:455-73.

2" Freemont AJ, Jones CJP. Light microscopic, histochemical and ultrastructural studies of human lymph node paracortical venules. J Anat (in press).

"Andrews P, Ford WL. Stoddart RW. Metabolic studies of highwalled endothelium of post capillary venules in rat lymph node. Blood Cells and Vessel Walls: functional interactions. Ciba Found Symp 1980;71 new series:211-30.

Requests for reprints to: Dr AJ Freemont, Department of Pathology, University of Manchester Medical School, Oxford Road, Manchester M13 9PT, England. 